\title{
Cut-and-paste clinical notes confuse care, say US internists
}

$\mathrm{E}$ fforts to simplify clinical notetaking have unwittingly turned the patient record into a kind of medical Mad Libs, say top internists in the United States.

The American College of Physicians (ACP) has launched an investigation in response to concerns that tickbox documentation and copy-paste data dumping are crowding out important nuance in notes.

"We migrated to this format because it made it easier for auditors to capture the data necessary to justify a certain level of billing," says Dr. Yul Ejnes, immediate past chair of ACP's board of regents. "There are checklists, medication lists, test orders, pages of past history copied forward, and yes-no phrases to show our work, but when it comes to what a doctor is thinking - the meat of the clinical note - there's not much in the way of narrative."

Gone are the days when a brief patient visit would require equally brief documentation. Now, even the most routine exams can generate reams of notes, as physicians err on the side of excess to audit-proof their records.

"God help the person who has to read a thoughtlessly created, but perhaps entirely accurate, electronically generated note," says Dr. Peter Basch, chair of ACP's medical informatics committee. "It doesn't convey in a precise way what one needs to know as part of a care team, and in an era of open notes, it doesn't convey anything to patients and their families."

The problem of "note bloat" has mushroomed with the widespread adoption of electronic medical records, which enable physicians to create generic narrative from drop-down menus and clone whole notes with a few clicks.

Such shortcuts are harmless when used to document routine visits, says Dr. Michael Barr, ACP's senior vice-

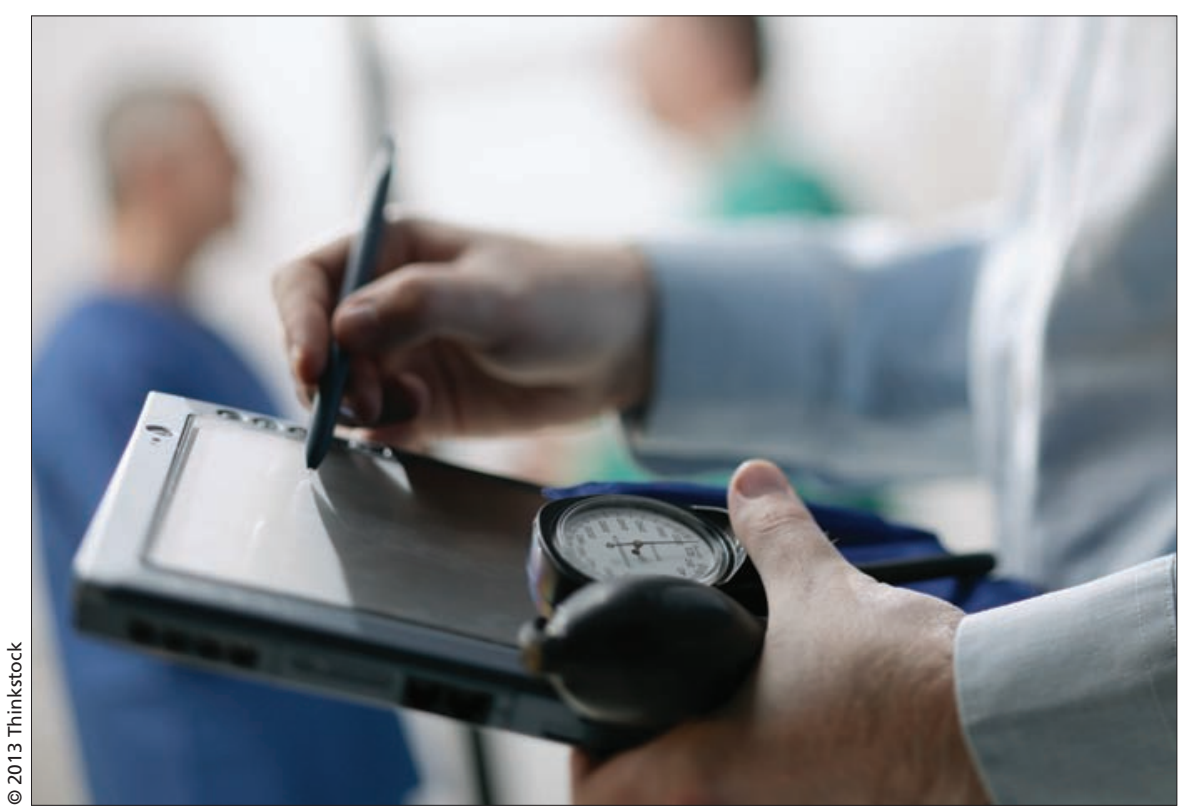

The problem of "note bloat" has mushroomed with the widespread adoption of electronic medical records.

president of medical practice. "If someone comes in with a sore throat, there are maybe five different questions you would ask, so using a template is pretty straight-forward."

But indiscriminate use can result in incomplete or inaccurate notes, and ultimately clinical errors, says Barr. "The danger is that you hear a heart murmur, but copy-forward an old note that doesn't document one, and you don't catch that."

The common practice of cloning notes also makes it difficult to distinguish where clinical plagiarism ends and billing fraud begins.

"People play to the test," says Dr. Robert Centor, chair-elect of ACP's board of regents. "I had a patient being followed by a surgery resident who wrote, or I should say cut-andpasted, the exact same note three days in a row. He showed up, but whether he examined the patient or not is anyone's guess because you can't tell from his notes."
The upshot of such cookie-cutter notes is that fewer physicians believe what they read in their patients' records, Centor adds. "When I get patients from emergency rooms, I often start over, because I don't get any useful information now."

Some physicians are trying to bridge the gap by adding narrative in free-text fields to create hybrid notes. But this takes extra time others may not have, says Ejnes.

More promising is progress on software that can translate free-text into the kind of structured data that make auditors happy, he adds. But such programs are a long way from mainstream implementation.

Ultimately, note bloat is a byproduct of the fee-for-service payment model, says Basch. "Without a cleavage of documentation from payment, there will always be this kind of ugly, gravitational pull." — Lauren Vogel, CMAJ

CMAJ 2013. DOI:10.1503/cmaj.109-4656 